\title{
Computed Tomography Colonography Phantom: Construction, Validation and Literature Review
}

\author{
Lukas Lambert, ${ }^{1, *}$ Alena Lambertova, ${ }^{1,2}$ Jan Danes, ${ }^{1}$ and Gabriela Grusova ${ }^{3}$ \\ ${ }^{1}$ Department of Radiology, First Faculty of Medicine, Charles University in Prague, Prague, Czech Republic \\ ${ }^{2}$ Department of Psychiatry, First Faculty of Medicine, Charles University in Prague, Prague, Czech Republic \\ ${ }^{3}$ Fourth department of Internal Medicine, First Faculty of Medicine, Charles University in Prague, Prague, Czech Republic \\ "Corresponding author: Lukas Lambert, Department of Radiology, General University Hospital in Prague, U Nemocnice 2, 12808 Prague 2, Czech Republic. Tel: +420-224962232, \\ Fax: +420-224963048, E-mail: lambert.lukas@gmail.com
}

Received 2015 July 28; Revised 2015 September 12; Accepted 2015 October 10.

\begin{abstract}
Background: Several dedicated computed tomography (CT) colonography phantoms have been described previously.

Objectives: To compare their pros and cons and describe the construction of a dedicated phantom that can be easily manufactured. Materials and Methods: We found 15 different phantom designs by literature search and compared their advantages and disadvantages based on their description and images. We tested various materials for density and mechanical properties and constructed a phantom from polypropylene pipes ( $30 \mathrm{~mm}$ and $50 \mathrm{~mm}$ in diameter, $52 \mathrm{~cm}$ in length). Haustral folds were created by heat shaping and 39 intermediate sessile polyps with a target size of 6-10 $\mathrm{mm}$ and two flat lesions were created from silicone. Nine polyps were attached to a fold. The model was placed in a $30-\mathrm{cm}$ barrel filled with water to simulate attenuation of human body. Attenuation of polyps was compared to intermediate polyps found in patients.

Results: None of the earlier colonic phantoms found in the literature incorporated all the properties that would ensure both reproducibility and validity of the model (including a rigid wall, density of the wall and polyps similar to human colon, at least two levels of distension and durability). In the present phantom, the average size of sessile polyps was $8.6 \pm 0.9 \mathrm{~mm}$ and their density was $53 \pm 24 \mathrm{HU}$. We found no significant difference in polyp density between simulated polyps in the phantom and polyps in human subjects $(\mathrm{P}=0.70)$. All polyps, with the exception of one flat lesion, were detected by computer aided detection.

Conclusion: We constructed and validated a CT colonography phantom with correct density allowing performance of reproducible experiments.
\end{abstract}

Keywords: Phantom, CT Colonography, Polyp, Review, Low-Dose

\section{Background}

With increasing innovation in imaging technologies such as computed tomography (CT), there is a growing need for performance validation (1). Basic phantoms have been established for the measurement of low- and highcontrast resolution, impulse response and CT calibration; some are shipped with CT scanners for routine testing and image quality calibration. More complex phantoms that simulate internal structures of the human torso including attenuation and shapes of various tissues are already commercially available; however, manufacturing complexities are generally reflected in prohibitive costs. Additionally, commercial phantoms do not always comply with specific requirements of a particular study regarding lesion shape, size, attenuation, number or location. In such cases a specific phantom must be commissioned.

\section{Objectives}

The aim of the present work was 1) to compare various phantom designs found by literature search and 2) to design, construct and validate a specific phantom for CT colonography (CTC) with multiple intermediate polyps that would be suitable for comparison of diagnostic performance of low-dose CTC among different scanners.

\section{Materials and Methods}

Initially we tested several materials (polyurethane resin, silicone, modeling clay, polyvinylchloride, polypropylene, silicone pipes, plexiglass and ex-vivo colon) for their suitability in constructing a colonic wall.

In materials classified as rigid pipes, we attempted to create a bend to simulate colonic anatomy. In general, there are three options to create bends: 1) heat shaping, 2) connecting a prefabricated elbow and 3) connecting two 
pipes with oblique ends. For heat shaping, the tube must be filled with loose material such as fine sand and the selected segment heated and carefully bent to avoid casing defects. Bends more than 60 degree are difficult to make. Conversely, a commercially available prefabricated elbow can be fixed to the end of pipe, thus achieving a bend of a defined shape without the risk of damaging the casing. The last option, fixing two ends of straight pipe together, results in a sharp bend. Finally, we chose polypropylene pipe with internal diameters of $50 \mathrm{~mm}$ and $30 \mathrm{~mm}$. A $80^{\circ}$ bend was created by heat shaping the $30 \mathrm{~mm}$ pipe and a $105^{\circ}$ bend with an elbow in the $50 \mathrm{~mm}$ pipe. Haustral folds were created by heat shaping in both pipes. The final length of each pipe was $52 \mathrm{~cm}$.

To simulate polyps, a material with suitable attenuation (density) corresponding to soft tissue (30 - $80 \mathrm{HU})$ that sticks firmly to the casing was required (2).

From the materials tested we chose silicone sealant as it has appropriate attenuation, can be processed easily and has satisfactory adherence. We attached 39 sessile polyps with a target size of 6-10 $\mathrm{mm}$ and two flat lesions onto the internal wall of the two pipes. Nine of the polyps were attached to a fold.

To ensure maximal reproducibility of intraluminal content, we simulated tagged stool by mixing iodine contrast material (Iomeron 350, Mallinckrodt Deutschland, Hennef, Germany) with canned baby food at a ratio of 1:40.

The pipes were placed in a $30 \mathrm{~cm}$ wide barrel and secured in place so that they would not float. The barrel was filled with water, closed by a water-tight lid and placed in a plastic container to prevent any damage to the scanner in case of leakage. The phantom was then scanned on a 256-slice scanner (Brilliance iCT 256; Philips Healthcare, Best, The Netherlands) with a standard abdominal protocol (peak voltage, $120 \mathrm{kV}$; tube current-time product, $120 \mathrm{mAs}$; rotation time, $0.75 \mathrm{~s}$; pitch, 0.60; collimation, $128 \times 0.625 \mathrm{~mm}$, no modulation) and the images were reconstructed in thin $0.9 \mathrm{~mm}$ sections. The images were reviewed on an advanced workstation (Philips Intellispace Portal, Philips Healthcare, Best, The Netherlands) using a dedicated CTC package with computer aided diagnosis (CAD). The size and density of each simulated polyp in the phantom was measured by a reader blinded to distribution of polyps and compared with 39 intermediate sessile polyps found in patients referred for CTC (14 males, 25 females, mean age $65 \pm 12$ years). This group was used only for validation of density and size of simulated polyps and measurement of water-equivalent diameter (WED) in the pelvis.

A literature search of PubMed was conducted using keywords arranged in the following phrase "((virtual colonoscopy) or colonography) and CT) and phantom)".
Statistical analyses were performed in GraphPad Prism (Graphpad Software, Inc., San Diego, CA, USA). The size and density of polyps were compared using t-test. A P value below 0.05 was considered significant.

\section{Results}

We constructed and validated a reproducible phantom for CTC using materials with similar attenuation to human colon (Figure 1). The average diameter of sessile polyps was $8.6 \pm 0.9 \mathrm{~mm}$ vs. $8.5 \pm 1.2 \mathrm{~mm}(\mathrm{P}=0.75)$ in the phantom vs. patients and their attenuation was $53 \pm 24 \mathrm{HU}$ vs. 52 $\pm 15 \mathrm{HU}(\mathrm{P}=0.69)$. All polyps except one flat lesion were detected by CAD (Figure 2-4). The average WED measured in pelvis in patients was $28.7 \mathrm{~cm}$ (ranged 24.7 to $36.2 \mathrm{~mm}$ ) and the WED of the barrel was $29.1 \mathrm{~cm}$ (when the empty "colon" was inserted) or $29.6 \mathrm{~cm}$ (with tagged stool).

The literature search yielded 74 results, 68 in English, from which 51 dealt with specific phantoms for CTC with simulated colonic lesions. Because several phantoms were used repeatedly and phantom designs were reused with slight modifications, only basic designs have been summarized in Table 1 .

\section{Discussion}

In this study, we constructed and validated colonic phantom with intermediate polyps needed for testing the diagnostic performance of various CT scanners in low-dose CTC.

The current literature holds that there is a six-level hierarchy to test the efficacy of diagnostic imaging tests beginning with technical performance, diagnostic performance, contribution to clinical diagnosis, improvement in treatment and outcome of patients and finally societal value at the very top (1). The technical performance of an imaging test can be measured directly. Image quality at different dose levels can be compared among different CT scanners using basic phantom modules for the assessment of low-contrast and high-contrast resolution, spatial resolution or by its evaluation by independent observers $(25,26)$. However, to test the diagnostic performance, i.e. how the method can detect a disease, a reference standard with known performance is needed. This can be performed on phantoms with simulated disease (polyp, mass, pulmonary nodule), animals with induced disease or human subjects with a disease established by a superior method. Even though testing diagnostic performance on patients has the greatest validity, it can hardly be used for comparison of different CT scanners, because the patient would have to be scanned several times. Practical applications 

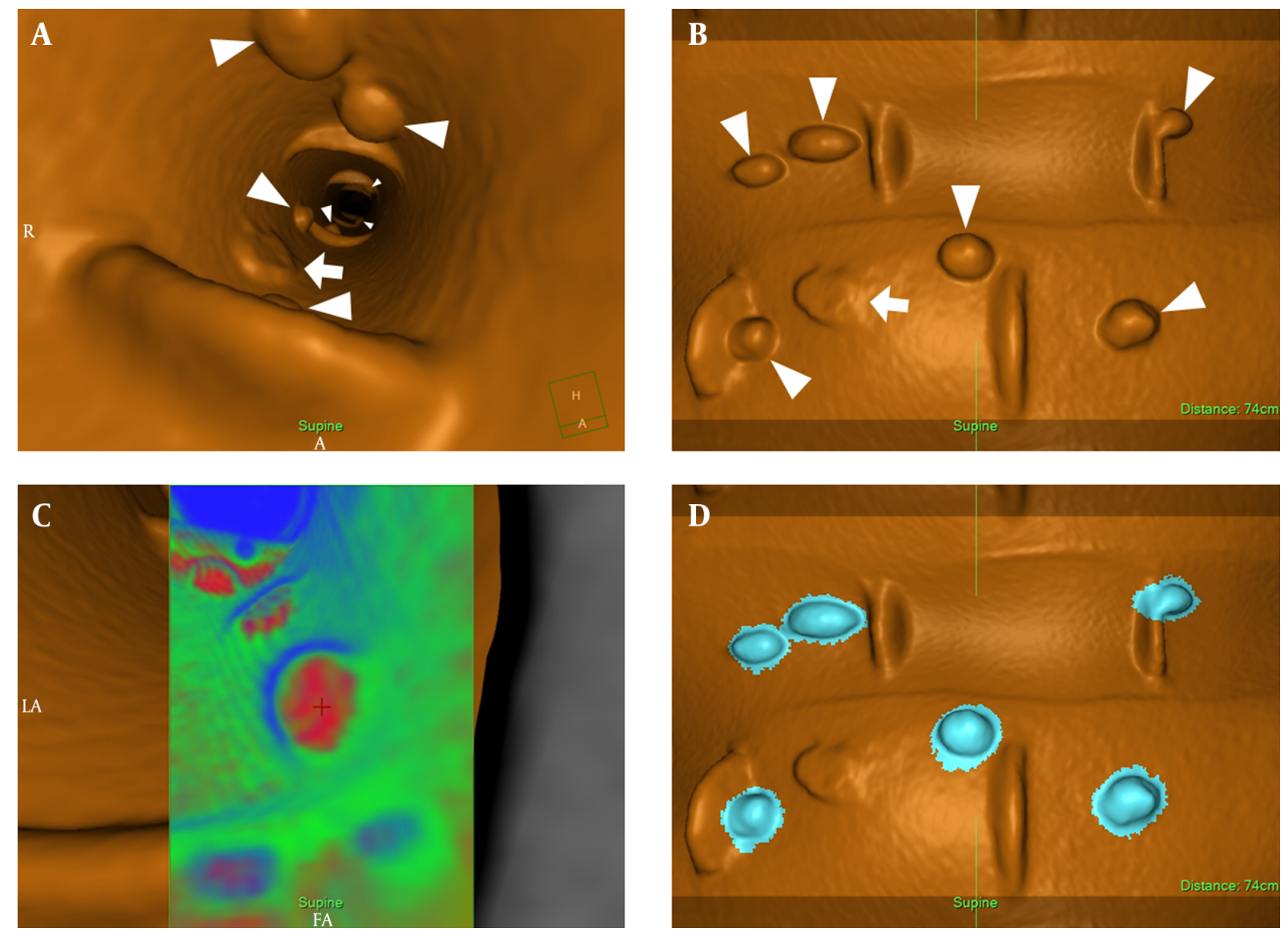

Figure 1. Virtual endoscopic (A,C) and fillet view (B,D) of the colonic phantom show several sessile polyps (arrowheads) and a flat lesion (arrow). Correct density of polyps is confirmed by translucency rendering (C) that shows red color, which represents soft tissue (so called "hot lesion"). Polyp candidates found by computer aided detection are marked blue (D).

of a dedicated CT colonography phantom include: 1 . optimization of acquisition protocol (tube voltage, tube current, slice thickness and radiation dose in general) and the reconstruction technique (filtered back projection vs. iterative reconstruction techniques), 2. optimization of stool tagging and electronic cleansing (including dual energy), 3. optimization and benchmarking of CAD, 4 . interscanner comparison of image quality and diagnostic performance vs. radiation dose.

Several designs of colonic phantoms reported in literature are summarized in Table 1 . The most popular phantoms, those used repeatedly or by several research groups included ex vivo porcine colon or colonic polyposis colectomy specimen, glass, plexiglass and plastic tube phantoms. Ex vivo colon is available from abattoir, it provides genuine anatomic detail and attenuation and colonic lesions can be easily created by ligation of the mucosa. But it needs inflation that results in shape variability and dete- riorates rapidly. Therefore, it cannot be used for interscanner comparison that would require absolutely constant shape, position and distension, which has been shown to affect polyp detectability (27). Glass and plexiglass have high attenuation $(\sim 150 \mathrm{HU})$ and a thick wall, but they are transparent, maintain their shape and do not require inflation. Plastic tube phantoms come in different shapes and are made of different materials. Commercially available corrugated Polyvinylchloride (PVC) tubing contains only small indentations that allow easy bending without compromising the flow, therefore its resemblance of haustral folds is very limited. Ordinary running pipes are usually made of PVC or polypropylene and their attenuation varies according to processing and additives. They maintain their shape when submerged and bends can be formed by heat molding or connecting a shoulder. If the phantom is straight, distribution of lesions in different planes can be achieved by repositioning with repeated scanning. Flexi- 
Table 1. Comparison of Colonic Phantoms for CT Colonography Previously Reported in the Literature

\begin{tabular}{|c|c|c|c|c|c|}
\hline Phantom Design, Casing & Polyps & Insufflation & Reproducibility & Advantages & Disadvantages \\
\hline \multicolumn{6}{|l|}{ Simulation } \\
\hline $\begin{array}{l}\text { Digital synthesis } \\
\text { from CTC data ( } 3 \text { ) }\end{array}$ & Digital synthesis & - & - & $\begin{array}{l}\text { Polyps of any size, shape and } \\
\text { density, genuine colon } \\
\text { anatomy }\end{array}$ & $\begin{array}{l}\text { Requires special software, } \\
\text { cannot be used for low-dose } \\
\text { testing }\end{array}$ \\
\hline \multicolumn{6}{|l|}{ Ex vivo } \\
\hline Porcine colon (5-7) & $\begin{array}{l}\text { Puckering the mucosa with } \\
\text { securing suture }\end{array}$ & Yes & Poor & $\begin{array}{l}\text { Readily available, } \\
\text { appropriate density of } \\
\text { polyps }\end{array}$ & $\begin{array}{l}\text { Needs insufflation, } \\
\text { deteriorates rapidly, draping } \\
\text { of adjacent mucosa }\end{array}$ \\
\hline $\begin{array}{l}\text { Colonic polyposis } \\
\text { colectomy specimen } \\
\text { (8) }\end{array}$ & Natural & Yes & Poor & Colon with natural polyps & $\begin{array}{l}\text { Size of polyps cannot be } \\
\text { controlled, deteriorates } \\
\text { rapidly, very limited } \\
\text { availability }\end{array}$ \\
\hline \multicolumn{6}{|l|}{ Flexible materials } \\
\hline Latex balloon (9) & Ham (meat) & Yes & Poor & Easy construction & $\begin{array}{l}\text { Poor reproducibility, needs } \\
\text { insufflation }\end{array}$ \\
\hline $\begin{array}{l}\text { Stereolithography } \\
\text { (silicone)(10) }\end{array}$ & Silicone & Yes & Average & $\begin{array}{l}\text { Genuine anatomy of the } \\
\text { colon with large and small } \\
\text { structures }\end{array}$ & $\begin{array}{l}\text { Soft-walled model, needs } \\
\text { insufflation }\end{array}$ \\
\hline $\begin{array}{l}\text { Thermoreversible } \\
\text { flexible plastic } \\
\text { material (Dubliplast) } \\
(11,12)\end{array}$ & $\begin{array}{l}\text { Thermoreversible flexible } \\
\text { plastic material (Dubliplast) }\end{array}$ & No & Excellent & $\begin{array}{l}\text { Molding of various shapes } \\
\text { including haustral folds and } \\
\text { polyps, correct attenuation } \\
\text { ( } 45 \mathrm{HU})\end{array}$ & $\begin{array}{l}\text { Elastic material needs } \\
\text { supporting structure, } \\
\text { straight without bends }\end{array}$ \\
\hline $\begin{array}{l}\text { Silastic (silicone } \\
\text { rubber) }(13,14)\end{array}$ & $\begin{array}{l}\text { Unknown material, low } \\
\text { density on image }\end{array}$ & No & Excellent & Reproducible & $\begin{array}{l}\text { High density of the wall ( } 200 \\
\text { HU), low density of polyps, } \\
\text { needs supporting structure }\end{array}$ \\
\hline Plexiglass $(15,16)$ & Plexiglass & No & Excellent & Several diameters of tubes & $\begin{array}{l}\text { No bends } \pm \text { haustral folds, } \\
\text { high density }(150 \mathrm{HU}) \text {, thick } \\
\text { wall }(2,8 \text {, and } 11 \mathrm{~mm})\end{array}$ \\
\hline Acrylic tube $(17,18)$ & Acrylic, plasticine & No & Excellent & Three diameters of tubes & $\begin{array}{l}\text { No bends or haustral folds, } \\
\text { thick wall ( } 5 \mathrm{~mm})\end{array}$ \\
\hline $\begin{array}{l}\text { Glass (borosilicate) } \\
(19,20)\end{array}$ & Solid water, epoxy resin & No & Excellent & $\begin{array}{l}\text { Excellent reproducibility, } \\
\text { various shapes of the colon } \\
\text { and polyps in different } \\
\text { shapes can be easily created }\end{array}$ & $\begin{array}{l}\text { Thick dense wall of the } \\
\text { colon, fragile material, } \\
\text { polyps made of solid water } \\
\text { have low density }\end{array}$ \\
\hline $\begin{array}{l}\text { Commissioned, } \\
\text { undisclosed material } \\
\text { (21) }\end{array}$ & $\begin{array}{l}\text { Undisclosed material with } \\
\text { density of } 10 \mathrm{HU}\end{array}$ & No & Excellent & Reproducible & $\begin{array}{l}\text { No polyps on haustral folds, } \\
\text { minimum polyp size } 8 \mathrm{~mm} \text {, } \\
\text { low density of walls and } \\
\text { polyps }\end{array}$ \\
\hline PVC pipe (22) & Glass beads & No & Excellent & Reproducible & High density of the wall \\
\hline $\begin{array}{l}\text { Corrugated plastic } \\
\text { tubing }(23,24)\end{array}$ & Wood & No & Excellent & Easy construction & $\begin{array}{l}\text { Corrugation is too fine to } \\
\text { mimic haustral folds, low } \\
\text { density of polyps (- }-370 \mathrm{HU}) \\
\text { and tubing }\end{array}$ \\
\hline PP pipe (this study) & Silicone & No & Excellent & $\begin{array}{l}\text { Reproducible, soft-tissue } \\
\text { attenuation, easy shaping of } \\
\text { polyps }\end{array}$ & Opaque \\
\hline
\end{tabular}

Abbreviations: PVC, polyvinylchloride; PP, polypropylene

ble plastic materials that can be easily shaped by casting

need supporting structure, so that they do not collapse 


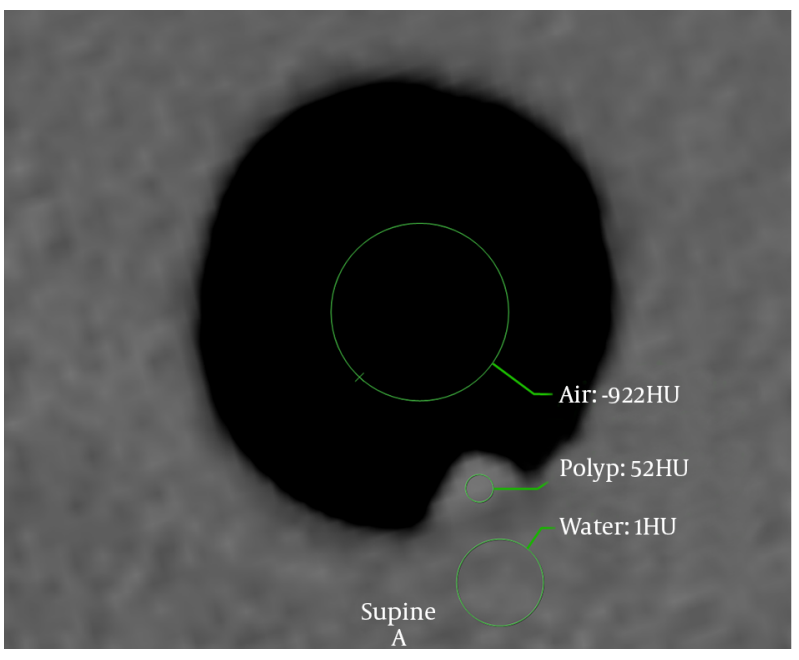

Figure 2. Density of intraluminal air (-922HU), simulated polyp (52HU) and water $(1 \mathrm{HU})$ surrounding the colonic phantom to simulate body attenuation shown in trans-axial thin slices (window 900/100HU).

when submerged.

From the presented colonic models, it is important to show that neither of them had soft-tissue attenuation of the colonic wall and polyps and high reproducibility at the same time. In our phantom, we used two different internal diameters representing a colonic segment with excellent and poor (but still evaluable) distension. Creating bends in a colonic phantom is necessary for distribution of polyps in all three dimensions in one scan. It also results in variation of the amount of water-equivalent attenuation in different parts of the phantom as encountered in patients. The average WED measured in patients was nearly identical to the WED of the phantom. However, bony structures in the pelvis contribute to image deterioration more than the equivalent amount of water.

Attenuation of colonic polyps is of importance. Polyps with lower density are more prone to disappear in the electronic noise in low-dose studies, especially if the reader prefers increasing the endoluminal rendering threshold (attenuation value above which voxels appear as colonic wall instead of intraluminal air), whereas polyps with too high density may escape CAD detection $(25,28)$.

The likelihood of a polyp to harbor malignancy depends on its size (29). It is unlikely for a diminutive polyp $(<6 \mathrm{~mm})$ to contain high grade dysplasia and such polyps do not need to be reported (30-32). Therefore, phantoms for CTC are designed with polyps from $6 \mathrm{~mm}$ in diameter and upwards. Intermediate polys $(6-10 \mathrm{~mm})$ constitute a benchmark for CTC for polyp detection and their discrimination from stool residue. Flat lesions that escape detec- tion more often than sessile polyps are less frequent and they pose a challenge even to CAD and therefore only two of them were included in the phantom. The number of polyps was chosen to be reasonable for reporting and with regard to statistics and memory washout so that locations of the polyps would be difficult to remember. In the process of evaluating studies, care should be taken to minimize recall bias by making sufficiently long intervals between reading sessions.

The phantom presented in this paper was validated with unenhanced CTC in patients with intermediate polyps. The phantom can be scanned empty or with simulated stool with tagging so as to reflect standard preparation protocols. To compare polyp detection among different scanners, the same mixture must always be used. This can be achieved using standard compounds (such as magnesium aluminum silicate or canned food for babies) mixed with tagging agents such as iodine contrast material or barium in constant proportion (14). However, reproducible distribution of simulated stool residue across the phantom cannot be guaranteed (Figure 4).

Scanner settings affect image quality, especially in lowdose acquisitions. Although a slice thickness of $2.5 \mathrm{~mm}$ is the recommended maximum, thinner slices are commonly used for a more accurate depiction of internal structure of a polyp candidate $(28,33)$.

Although polyp detection and polyp conspicuity are important, this can be to a great extent assisted by CAD (34). However, what shows expertise in CTC is the ability and confidence in discriminating between true polyps and polyp mimics such as stool residue and folds (35).

This study had several limitations. The attenuation of the phantom wall could not be reliably measured due to partial volume averaging. Therefore, its density was compared to the density of simulated polyps. Another limitation is that in real conditions the attenuation of body is inhomogeneous, especially in regions with bony structures such as spine and pelvis, constituting a limit for low dose imaging $(25,28)$.

In conclusion, we designed and verified a CT colonography phantom with 39 intermediate polyps and two flat lesions of soft tissue attenuation. Furthermore, we discussed limitations of previously reported models for reproducibility, attenuation, durability and other properties needed to ensure their correctness when comparing performance of different CT scanners.

\section{Footnotes}

Authors' Contribution: Study concept and design: Lukas Lambert, Alena Lambertova and Jan Danes; acquisition of 

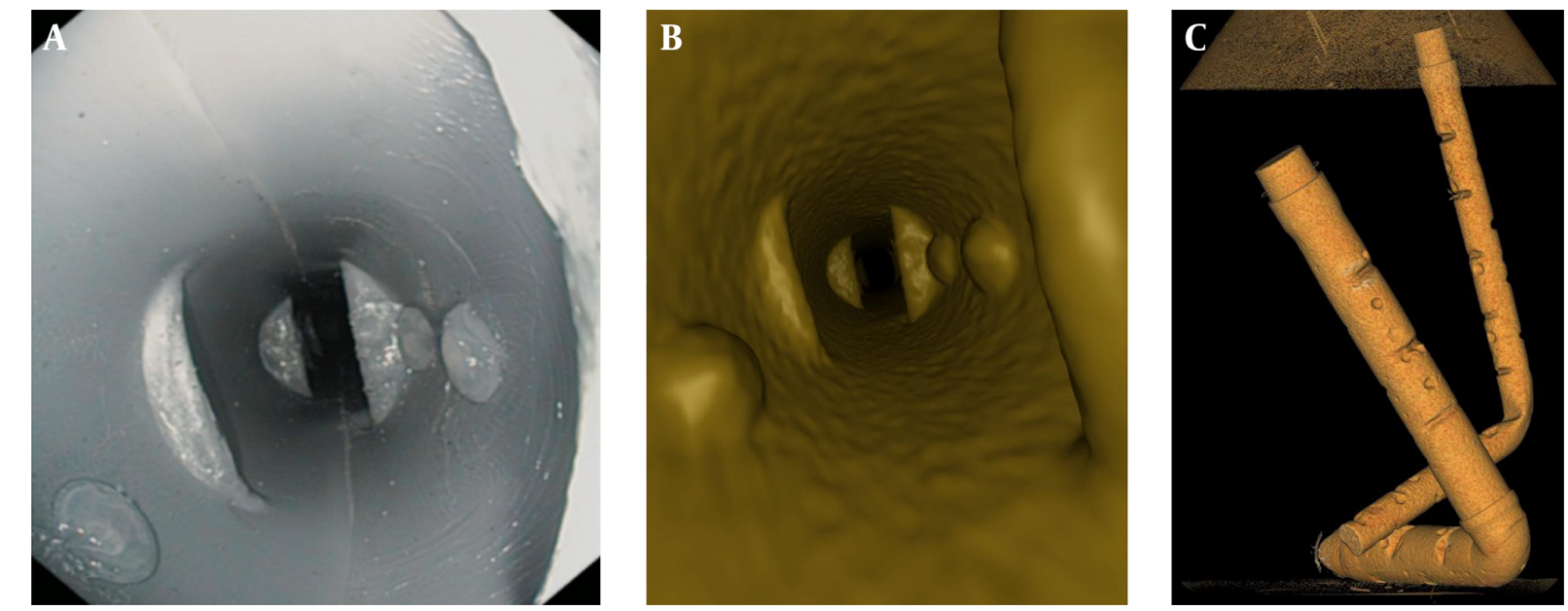

Figure 3. Optical (A) and virtual (B) endoscopic views of the phantom show haustral folds and three sessile polyps. Volume-rendered image of the phantom is shown on part C.
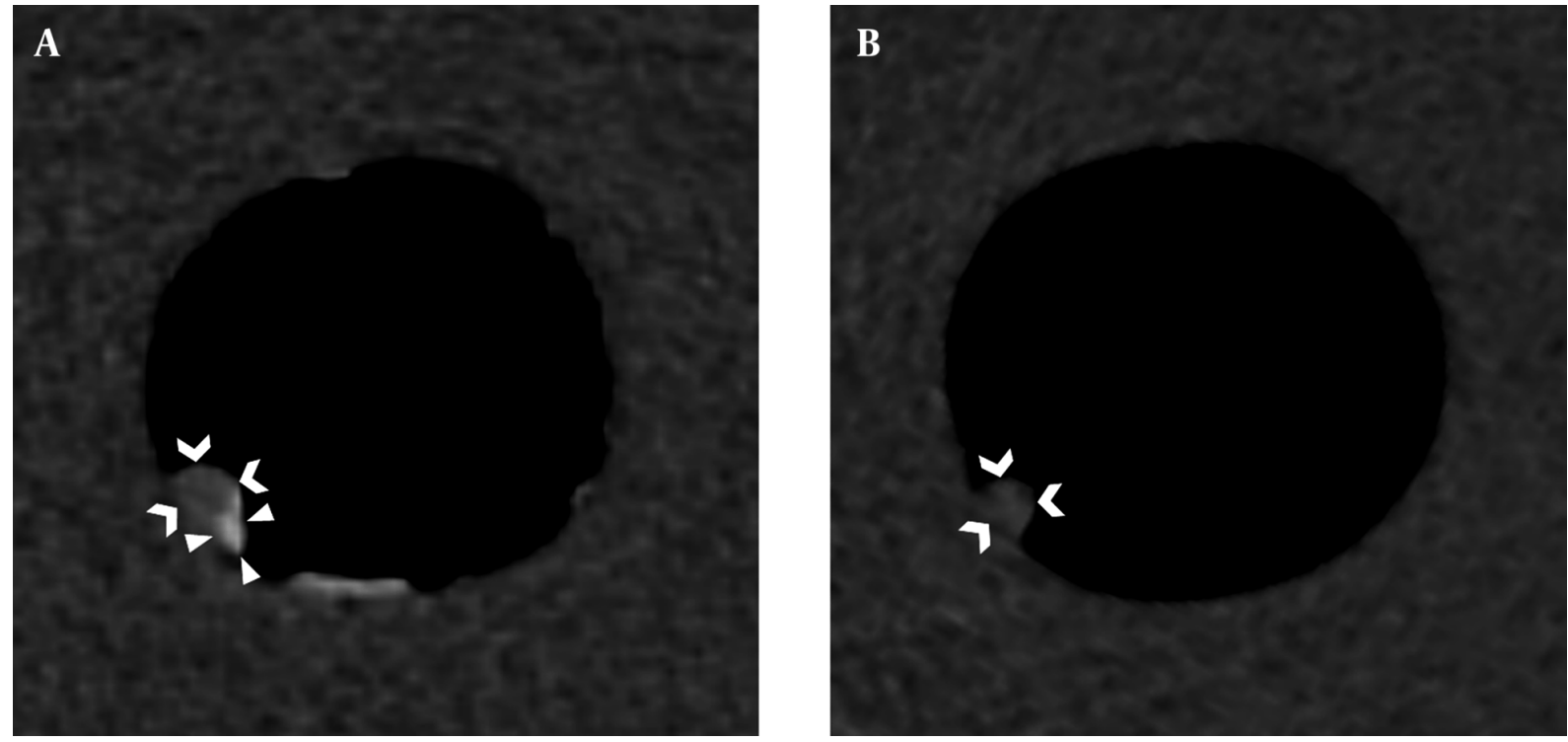

Figure 4. A,B, Simulated stool residue (canned baby food) tagged with iodine contrast material appear as dense material (arrowheads) and therefore can be easily distinguished from an intermediate sessile polyp (chevrons).

data: Lukas Lambert, Gabriela Grusova; analysis and interpretation of data: Lukas Lambert, Alena Lambertova; drafting of the manuscript: Lukas Lambert, Alena Lambertova and Jan Danes; critical revision of the manuscript for important intellectual content: all; statistical analysis: Lukas Lambert; administrative, technical, and material support: all; study supervision: Lukas Lambert.

Financial Disclosure: The authors declared no conflicts of interest

Funding/Support: This study was supported by the fol- lowing grants: PRVOUK P27/LF1/1, NT13302-4/2012,15-27941A.

\section{References}

1. Sunshine JH, Applegate KE. Technology assessment for radiologists. Radiology. 2004;230(2):309-14. doi: 10.1148/radiol.2302031277. [PubMed: 14752174].

2. Oto A, Gelebek V, Oguz BS, Sivri B, Deger A, Akhan O, et al. CT attenuation of colorectal polypoid lesions: evaluation of contrast en- 
hancement in CT colonography. Eur Radiol. 2003;13(7):1657-63. doi: 10.1007/s00330-002-1770-y. [PubMed:12835982].

3. Karadi C, Beaulieu CF, Jeffrey RJ, Paik DS, Napel S. Display modes for CT colonography. Part I. Synthesis and insertion of polyps into patient CT data. Radiology. 1999;212(1):195-201. doi: 10.1148/radiology.212.1.r99j125195. [PubMed:10405742].

4. Branschofsky M, Vogt C, Aurich V, Beck A, Modder U, Cohnen M. Feasibility of ultra-low-dose multi-detector-row CT-colonography: detection of artificial endoluminal lesions in an in-vitro-model with optimization of image quality using a noise reduction filter algorithm. Eur J Med Res. 2006;11(1):13-9. [PubMed: 16504955].

5. Dachman AH, Lieberman J, Osnis RB, Chen SY, Hoffmann KR, Chen CT, et al. Small simulated polyps in pig colon: sensitivity of CT virtual colography. Radiology. 1997;203(2):427-30. doi: 10.1148/radiology.203.2.9114099. [PubMed: 9114099].

6. Choi JI, Kim SH, Kim SH, Park HS, Lee JM, Lee JY, et al. Comparison of accuracy and time-efficiency of CT colonography between conventional and panoramic 3D interpretation methods: an anthropomorphic phantom study. Eur J Radiol. 2011;80(2):68-75. doi: 10.1016/j.ejrad.2010.08.022. [PubMed: 20875938].

7. Park SH, Choi EK, Lee SS, Byeon JS, Jo JY, Kim YH, et al. Polyp measurement reliability, accuracy, and discrepancy: optical colonoscopy versus CT colonography with pig colonic specimens. Radiology. 2007;244(1):157-64. doi: 10.1148/radiol.2441060794. [PubMed: 17507724].

8. Taylor S, Slater A, Honeyfield L, Burling D, Halligan S. CT colonography: effect of colonic distension on polyp measurement accuracy and agreement-in vitro study. Acad Radiol. 2006;13(7):850-9. doi: 10.1016/j.acra.2006.03.018. [PubMed: 16777559].

9. Na Y, Kim JS, Whiting BR, Bae KT, editors. Automatic detection of polyps from multislice ct images using $3 \mathrm{~d}$ morphologic matching algorithm: Phantom study. Medical Imaging 2003. 2003; International Society for Optics and Photonics; pp. 877-81.

10. Wong KH, Norris JA, Holmes Iii DR, Barton MD, Davis BJ, Bieszczad J, et al. Anatomically correct deformable colon phantom. 2011 ;7964:79642X. doi: 10.1117/12.878173.

11. Wessling J, Fischbach R, Meier N, Allkemper T, Klusmeier J, Ludwig K, et al. CT colonography: Protocol optimization with multidetector row CT-study in an anthropomorphic colon phantom. Radiology. 2003;228(3):753-9. doi: 10.1148/radiol.2283020928. [PubMed: 12954895].

12. Wessling J, Fischbach R, Borchert A, Kugel H, Allkemper T, Osada N, et al. Detection of colorectal polyps: comparison of multidetector row CT and MR colonography in a colon phantom. Radiology. 2006;241(1):125-31. doi: 10.1148/radiol.2411050292. [PubMed: 16908674].

13. Flicek KT, Hara AK, Silva AC, Wu Q, Peter MB, Johnson CD. Reducing the radiation dose for CT colonography using adaptive statistical iterative reconstruction: A pilot study. AJR Am J Roentgenol. 2010;195(1):12631. doi: 10.2214/AJR.09.3855. [PubMed: 20566805].

14. Johnson KT, Carston MJ, Wentz RJ, Manduca A, Anderson SM, Johnson $\mathrm{CD}$. Development of a cathartic-free colorectal cancer screening test using virtual colonoscopy: a feasibility study. AJR Am J Roentgenol. 2007;188(1):29-36. doi: 10.2214/AJR.05.1484. [PubMed: 17179324].

15. de Vries AH, Venema HW, Florie J, Nio CY, Stoker J. Influence of tagged fecal material on detectability of colorectal polyps at CT: phantom study. AJR Am J Roentgenol. 2008;191(4):1101. doi: 10.2214/AJR.07.3740. [PubMed: 18806150].

16. Laghi A, Iannaccone R, Mangiapane F, Piacentini F, Iori S, Passariello R. Experimental colonic phantom for the evaluation of the optimal scanning technique for CT colonography using a multidetector spiral CT equipment. Eur Radiol. 2003;13(3):459-66. doi: 10.1007/s00330002-1671-0. [PubMed: 12594547].

17. van Wijk C, Florie J, Nio CY, Dekker E, de Vries AH, Venema HW, et al. Protrusion method for automated estimation of polyp size on CT colonography. AJR Am J Roentgenol. 2008;190(5):1279-85. doi:
10.2214/AJR.07.2865. [PubMed: 18430844].

18. Springer P, Stohr B, Giacomuzzi SM, Bodner G, Klingler A, Jaschke W, et al. Virtual computed tomography colonoscopy: artifacts, image quality and radiation dose load in a cadaver study. Eur Radiol. 2000;10(1):183-7. [PubMed: 10663741].

19. Fletcher JG, Booya F, Melton Z, Johnson K, Guendel L, Schmidt B, et al. Automated polyp measurement with CT colonography: preliminary observations in a phantom colon model. AJR Am J Roentgenol. 2007;188(4):945-52. doi: 10.2214/AJR.06.1169. [PubMed: 17377028].

20. Johnson KT, Johnson CD, Anderson SM, Bruesewitz MR, McCollough $\mathrm{CH}$. CT colonography: determination of optimal CT technique using a novel colon phantom. Abdom Imaging. 2004;29(2):173-6. doi: 10.1007/s00261-003-0069-z. [PubMed: 15290942].

21. Zalis ME, Perumpillichira JJ, Kim JY, Del Frate C, Magee C, Hahn PF. Polyp size at CT colonography after electronic subtraction cleansing in an anthropomorphic colon phantom. Radiology. 2005;236(1):11824. doi: 10.1148/radiol.2361040231. [PubMed: 15987967].

22. Virmani S, Lev-Toaff A, Ciancibello L. Automatic polyp detection and measurement with computed tomographic colonography: A phantom study. Biomed Imaging Interv J. 2009;5(3):15. doi: 10.2349/biij.5.3.e15. [PubMed: 21611052].

23. Punwani S, Halligan S, Irving P, Bloom S, Bungay A, Greenhalgh $\mathrm{R}$, et al. Measurement of colonic polyps by radiologists and endoscopists: who is most accurate?. Eur Radiol. 2008;18(5):874-81. doi: 10.1007/s00330-007-0830-8. [PubMed: 18176807].

24. Boyce CJ, Vetter JR, Pickhardt PJ. MDCT artifact related to the intrascan gravitational flow of opacified luminal fluid (the "Dense Waterfall" sign). Abdom Imaging. 2012;37(2):292-6. doi: 10.1007/s00261-0119731-z. [PubMed: 21465109].

25. Lambert L, Danes J, Jahoda J, Masek M, Lisy J, Ourednicek P. Submilisievert ultralow-dose CT colonography using iterative reconstruction technique: a feasibility study. Acta Radiol. 2015;56(5):517-25. doi: 10.1177/0284185114533683. [PubMed: 24855290].

26. Love A, Olsson ML, Siemund R, Stalhammar F, Bjorkman-Burtscher IM, Soderberg M. Six iterative reconstruction algorithms in brain CT: a phantom study on image quality at different radiation dose levels. $\mathrm{Br}$ J Radiol. 2013;86(1031):20130388. doi: 10.1259/bjr.20130388. [PubMed: 24049128].

27. Taylor SA, Halligan S, Goh V, Morley S, Bassett P, Atkin W, et al. Optimizing colonic distention for multi-detector row CT colonography: effect of hyoscine butylbromide and rectal balloon catheter. $R a$ diology. 2003;229(1):99-108. doi: 10.1148/radiol.2291021151. [PubMed: 12944595].

28. Lambert L, Ourednicek P, Jahoda J, Lambertova A, Danes J. Modelbased vs hybrid iterative reconstruction technique in ultralow-dose submillisievert CT colonography. Br J Radiol. 2015;88(1048):20140667. doi: 10.1259/bjr.20140667. [PubMed: 25605346].

29. Summers RM. Polyp size measurement at CT colonography: what do we know and what do we need to know?. Radiology. 2010;255(3):70720. doi: 10.1148/radiol.10090877. [PubMed: 20501711].

30. Bretagne JF, Manfredi S, Piette C, Hamonic S, Durand G, Riou F. Yield of high-grade dysplasia based on polyp size detected at colonoscopy: a series of 2295 examinations following a positive fecal occult blood test in a population-based study. Dis Colon Rectum. 2010;53(3):339-45. doi: 10.1007/DCR.0b013e3181c37f9c. [PubMed: 20173483].

31. Sakamoto T, Matsuda T, Nakajima T, Saito Y. Clinicopathological features of colorectal polyps: evaluation of the predict, resect and discard strategies. Colorectal Disease. 2013;15(6):295-300.

32. Zalis ME, Barish MA, Choi JR, Dachman AH, Fenlon HM, Ferrucci JT, et al. CT colonography reporting and data system: a consensus proposal. Radiology. 2005;236(1):3-9. doi: 10.1148/radiol.2361041926. [PubMed: 15987959].

33. Yee J, Weinstein S, Morgan T, Alore P, Aslam R. Advances in CT Colonography for Colorectal Cancer Screening and Diagnosis. J Cancer. 2013;4(3):200-9. doi: 10.7150/jca.5858. [PubMed: 23459511]. 
34. Lubner MG, Pooler BD, Kitchin DR, Tang J, Li K, Kim DH, et al. Sub-milliSievert (sub-mSv) CT colonography: a prospective comparison of image quality and polyp conspicuity at reduced-dose versus standard-dose imaging. Eur Radiol. 2015;25(7):2089-102. doi: 10.1007/s00330-015-3603-9. [PubMed: 25903700].

35. Pickhardt PJ, Kim DH. CT colonography: pitfalls in interpretation. Radiol Clin North Am. 2013;51(1):69-88. doi: 10.1016/j.rcl.2012.09.005. [PubMed: 23182508]. 